\title{
APLICAÇÃO DE CELULASES IMOBILIZADAS NAHIDRÓLISE DE Brachiariabrizantha
}

\author{
T.F. PACHECO ${ }^{1}$, T.D.MENDES ${ }^{1}$, C.M.POLETTO ${ }^{1}$, T.F.C.SALUM ${ }^{1}$, T.C.R.LEITE ${ }^{2}$, \\ R. GAMBETTA ${ }^{1}$, D.S.R. GAMBETTA ${ }^{1}$ \\ ${ }^{1}$ Embrapa Agroenergia, Laboratório de Processos Bioquímicos \\ 2 Universidade Federal da Bahia, Biotecnologia \\ E-mail para contato:dasciana.rodrigues@embrapa.br
}

\begin{abstract}
RESUMO -A aplicação de celulases imobilizadas na desconstrução de biomassas possibilita melhorias para este processo, como o reuso de enzimas e maior quantidade de açúcar produzido por massa do biocatalisador. O objetivo deste trabalho foi desenvolver um biocatalisador para aplicação na hidrólise de holocelulosede braquiária. Celulases de um extrato bruto comercial foramimobilizadas por ligação covalente em quitosana ativada com glutaraldeído.As atividades do biocatalisador foram (em U/g): 0,92 ( $\alpha$-celulose); 8,69(celobiose); 4,74(carboximetilcelulose) e 0,13(avicel). O desempenho da enzima imobilizada em relação à enzima solúvel aumentou de 5,9\% aos 30 minutos de hidrólise para $11 \%$ após 18 horas de hidrólise. Isto ocorre, provavelmente, pela estabilização e resistência à inibição, ambos adquiridos após imobilização. A hidrólise de biomassa pré-tratada utilizando enzima imobilizada resultou naconversão de $79,5 \%$ da celulose (16 g/L de glicose). Este biocatalisador foi reutilizado, e redução de $52 \%$ no seu desempenho foi observada na segunda etapa de hidrólise. Concluiu-se que é possível preparar celulases imobilizadas eficazes e reutilizá-las em reações de hidrólise.
\end{abstract}

\section{INTRODUÇÃO}

Atualmente a aplicação de celulases para a desconstrução de biomassa vegetal tem ganhado grande destaque devido à crescente demanda por combustíveis e outros produtos de interesse da indústria química, os quais sejam obtidos a partir de fontes renováveis e por meio de processos ambientalmente favoráveis.

Os processos em larga escala que visam à utilização de celulases para a desconstrução de biomassa devem apresentar elevados valores de rendimento, concentração de açúcares fermentescíveis e produtividade. Entretanto, nesta escala, as dificuldades relacionadas ao custo, estabilidade, recuperação e reuso das enzimas são grandes desafios para viabilizar técnica e economicamente o processo (Ungureanet al., 2013).O uso de celulases imobilizadas é interessante porque possibilita o reuso das enzimas, e consequentemente o aumento da quantidade de açúcares fermentescíveis produzida por massa do catalisador.

Várias estratégias de imobilização têm sido propostas para celulases, por exemplo, entrecruzamento, sistema de ultrafiltração, sistema de duas fases aquosas, encapsulamento, 
adsorção e ligação covalente em suportes insolúveis, solúveis ou reversivelmente solúveis (Vieira et. al., 2011;Liang e Cao, 2012; Mao et al., 2006).Cada uma destas estratégias apresenta vantagens e desvantagens relacionadas a toxicidade, biodegradabilidade, custo de materiais e reagentes utilizados para a imobilização, tempo gasto e complexidade no preparo do biocatalisador, desempenho do biocatalisador, etc.

Entre as estratégias de imobilização de celulases, o entrecruzamento e a ligação em suporte sólido são as mais descritas na literatura. O preparo de biocatalisadores usando estas técnicas envolve ligações covalentes, as quais são irreversíveis no meio reacional em que o biocatalisador geralmente é utilizado, ou seja, temperatura de aproximada $50{ }^{\circ} \mathrm{C}$ e $\mathrm{pH} 5,0$. Além disso, este tipo de ligação promove mudanças estruturais nas enzimas que podem elevar sua estabilidade operacional.

Desde 1980, muitos esforços vêm sendo feitos para viabilizar a aplicação de celulases em diferentes processos industriais, mas a descoberta de celulases estáveis e de estratégias adequadas para reutilização destas ainda são grandes desafios para a comunidade científica. A imobilização de celulases é complexa, pois trata da interação de, no mínimo, nove enzimas diferentes (considerando os complexos enzimáticos comerciais) com diferentes suportes que podem ser ativados por diferentes métodos (Ogeda e Petri, 2010). Portanto a estrutura do suporte e/ou método de imobilização devem ser adequados para acomodar todo o conjunto de enzimas com o mínimo possível de perda de suas atividades catalíticas (Ungureanet al., 2013).

Centenas de trabalhos foram publicados sobre a imobilização de celulases, e a grande maioria destes avaliam o desempenho do biocatalisador utilizando carboximetilcelulose como substrato, o qual é solúvel em água. Entretanto, o substrato natural para estes biocatalisadores é insolúvel em água. Dentre os poucos trabalhos que avaliaram o desempenho de celulases imobilizadas em substratos sólidos, destacam-se os trabalhos de Adriano et al., 2008; Zhang et al., 2010; Jordan et al., 2011;Xuet al., 2011; e Lianget al., 2012.

O objetivo deste trabalho foi preparar um biocatalisador com celulases imobilizadas para a desconstrução de braquiária. A estratégia utilizada aqui foi a imobilização covalente em quitosana, a qual é uma técnica rápida, simples e faz uso de suporte de baixo custo.Para avaliar o desempenho do biocatalisador produzido foram utilizados substratos sintéticos e biomassa vegetal submetida apré-tratamento químico.

\section{MATERIAIS E MÉTODOS}

O estudo da imobilização das celulases foi dividido em quatro etapas principais: (a) Caracterização do extrato enzimático quanto ao teor e perfil de proteína,além da determinação das atividades total (FPase) e individuais (CMCase, avicelase e celobiase), (b) Imobilização covalente em quitosana, (c)Pré-tratamento da biomassa, e(d) Aplicação dos derivados imobilizados na hidrólise de biomassa pré-tratatada, cujo os procedimentos são descritos a seguir.

\subsection{Materiais}

Os principais materiais utilizados neste trabalho foram: Celulase CellicCtec2, doado pela Novozymes; Brachiariabrizantha,doada pela Embrapa Cerrados; padrões grau HPLC de glicose e 
celobiose adquiridos da Sigma Aldrich. Carboximetilcelulose, avicel, albumina do soro bovino, glutaraldeído, a celulose, kit para dosagem de glicose da Bioclin, quitosana (Aldrich/MKBH1168V); gel gradiente 8-16\% da GE, padrão de massa molecular de proteína da Invitrogen, kit para ensaio de proteínas com ácido binciconínico - BCA da ThermoScientific.

Os principais equipamentos utilizados foram: espectrofotometro multimodal com absorbância UV/VIS, modelo: SPECTRAMAXM3 da Molecular Devices; ultra turrax modelo: T25 digital S1 da IKA; banho maria modelo 316-6dn da Nova Ética, centrífuga refrigerada modelo z326k da HermleLabortechnik, sistema vertical de eletroforese modelo LCV10x10 da Loccus Biotecnologia, e cromatógrafo a líquido modelo 1260 infinity da Agilent Technology.

\subsection{Métodos}

Determinação de proteína: A determinação de proteína foi realizada usando kit para ensaio de proteínas com ácido binciconínico.

Eletroforese: Amostras deCellicCtec2 foram aquecidas em tampão de amostras eaplicadas aogel de gradiente 8-16 \% e tampão de corrida Tris- $\mathrm{HCl}$, ambos adquiridos comercialmente e prontos para uso. A corrida foi realizada sob $160 \mathrm{~V}, 20 \mathrm{~W}$ e $100 \mathrm{~mA}$ por 60 minutos. Ao final da corrida as proteínas distribuídas no gel foram coradas utilizando solução corante (Comassie). O excesso de corante foi removido por meio de diversas lavagens com água destilada em micro-ondas (até fervura).

AtividadesFPase, CMCase e Celobiase: Estas atividade foram determinadas com base na metodologia desenvolvida por Ghose(1987)e adaptada por Xiao(2004). Uma unidade de atividade (FPase - FPU ou CMCase - $\mathrm{U}_{\mathrm{CMC}}$ ) foi definida como a quantidade de enzima capaz de liberar 1 micromol de açúcar redutor nas condições do ensaio. Para celobiase, uma unidade de atividade (CBU) foi definida como a quantidade de enzima capaz de liberar 1 micromol de glicose nas condições do ensaio.Os ensaios foram realizados no mínimo em triplicata.

Atividade avicelase: A atividade de exoglicanase foi realizada utilizando o mesmo procedimento descrito para a atividade de CMCase, entretanto, substituindo a carboximetilcelulose por avicel. Uma unidade de avicelase é definida como a quantidade de enzima libera1 $\mu \mathrm{mol}$ de açúcar redutor por minuto nas condições descritas no procedimento.

Atividade em $\alpha$-celulose: Para medir a atividade de celulases imobilizadas, foi utilizadasolução de $\alpha$-celulose (pó contendo frações cristalinas e amorfas) de concentração 35 $\mathrm{mg} / \mathrm{mL}$ de maneira similar à descrita para atividade FPase.O procedimento foi feito em reator encamisado contendo $15 \mathrm{~mL}$ do meio reacional. Utilizou-se $10 \mathrm{uL}$ do extrato bruto enzimático e $0,1 \mathrm{~g}$ úmido da celulase imobilizada na reação de hidrólise que durou 30 minutos, sob agitação magnética.

Determinação das atividades celobiase, CMCase e avicelase para celulases imobilizada: Estas atividades foram realizadas de modo similar ao procedimento descrito para as celulases solúveis, entretanto em um maior volume reacional (mantendo a proporção entre os componentes), o qual foi mantido em reatores de vidro encamisados sob agitação magnética. 
Preparo e ativação do gel de quitosana: O procedimento de preparo e ativação do gel de quitosana foi realizado segundo metodologia descrita por Budrieneet al. (2005) com poucas modificações. Todas as etapas deste procedimento foram conduzidas $50^{\circ} \mathrm{Csob}$ agitação mecânica. A quitosana (6 g) foi dissolvida em ácido acético $2 \%(300 \mathrm{~mL})$, após30 minutos $450 \mathrm{~mL}$ de solução de $\mathrm{KOH}$ 0,5 M foi adicionado. Após 30 minutos a ativação do gel foi realizada pela adição de $4,5 \mathrm{~mL}$ de glutaraldeído $(25 \% \mathrm{~m} / \mathrm{m})$. Depois de 15 minutosfoi adicionado gelo à mistura para interromper a reação. A solução foi filtrada à vácuo em funil de buchner e o sólido obtido foi abundantemente lavado com água destilada.

Imobilização de celulase: CellicCtec $2(240 \mathrm{mg}$ de proteína/mL) foi diluído numa razão 1:50 em solução decitrato, $\mathrm{pH}$ 8. Em seguida $200 \mathrm{~mL}$ desta solução foi adicionada a 60,3 g do gel ativado (15,9 mg de proteína por grama do suporte), e a mistura foi mantida sob agitação magnética durante $1 \mathrm{~h}$. Para verificar a inativação da enzima nas condições de imobilização, $50 \mathrm{~mL}$ da solução de enzima foi mantido sob os mesmos valores de agitação, $\mathrm{pH}$ e temperaturado reator de imobilização, porém sem quitosana.

Pré-tratamentoB. brizantha: $\mathrm{O}$ pré-tratamento foi realizado em duas etapas, a primera com ácido sulfúrico 1,5\% (v/v), numa razão de 1:10 m/v (biomassa: solução ácida). A mistura foi autoclavada por 30 minutos a $121^{\circ} \mathrm{C}$. Após resfriamento, o sólido remanescente foi lavado e novamente submetido aautoclavagem seguindo o mesmo procedimento descrito anteriormente, substituindo a solução ácida por solução de hidróxido de sódio $4 \% \mathrm{~m} / \mathrm{v}$. O sólido remanescente foi exaustivamente lavado com água destilada fervente e armazenado a $4^{\circ} \mathrm{C}$ para posteriores experimentos de hidrólise enzimática.

Caracterização de B.brizantha: A biomassa in natura e pré-tratada foi caracterizada para determinação do teor de celulose, segundo a metodologia de Gouveia et al.(2009). Para esse procedimento, primeiramente foi determinado o peso seco dos materiaispré-tratados e in natura, realizando procedimento de secagem a $45{ }^{\circ} \mathrm{C}$ quando necessário.

Hidrólise enzimática de B.brizantha:A biomassa pré-tratada apresentou umidade de $75,5 \%$ e teor de celulose de $80,2 \%$ em base seca. As hidrólises do material pré-tratado foram realizadas utilizando $2 \%$ de celulose $(\mathrm{m} / \mathrm{v})$ e o volume reacional foi de $15 \mathrm{~mL}$. Foram adicionadas aos reatores de hidrólise a mesma quantidade (1FPU) de celulases livre e imobilizada $(1,09 \mathrm{~g}$ de celulase imobilizada e $0,007 \mathrm{~mL}$ do extrato enzimático).A hidrólise ocorreu em reator encamisado, a $50{ }^{\circ} \mathrm{C}$ e agitação magnética. Como controle, uma suspensão da celulase imobilizada sem o substratofoi mantida nas mesmas condições de hidrólise. Alíquotas foram retiradas nos interavalosde 0, 5, 22 e 24 horas. E os açúcares liberados foram analisados por cromatografia líquida. Para verificar a reusabilidade da celulase imobilizada, após a hidrólise da biomassa, o sólido remanescente (lignina, celulose não hidrolisada e celulase imobilizada) foi lavado e novamente adicionado ao reator para outro ciclo de hidrólise. Este procedimento foi repetido até observar perda de $50 \%$ ou menos do desempenho do biocatalisador.

\section{RESULTADOS E DISCUSSÃO}

Os resultados deste estudo serão apresentados em três tópicos pricipais: (a) Dados da caracterização do extrato enzimático bruto; (b) Dados da imobilização; (c)Dados da hidrólise de biomassa pré-tratada utilizando celulases solúveis e imobilizadas. 


\subsection{Caracterização do extrato enzimático}

Dosagem de proteína e análise da distribuição de peso molecular: O teor de proteína determinado pelo método do ácido binciconínico foi de $240 \mathrm{mg} / \mathrm{ml}$ e a distribuição de tamanho molecular pode ser observado no gel de eletroforese da Figura 1.

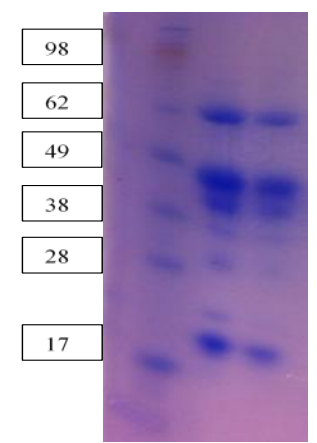

Figura 1 - Eletroforese de CellicCtec2. Linha 1: padrão, linha 2: CellicCtec 2 diluição 1:50 e linha 3: CellicCtec 2 diluição 1:100.

Sete bandas de proteínas contidas no extrato enzimático CellicCtec2são observadas numa faixa de 20 a $60 \mathrm{kDa}$. Estas proteínas são relativamente pequenas, o que minimiza problemas de transferência de massa durante a imobilização. É provável que em uma mesma banda haja mais que um tipo de proteína, visto que o complexo enzimático pode conter proteínas de tamanho muito próximos, para os quais a resolução nesta análise não é possível.

Dosagem de atividades enzimáticas: Em alguns procedimentos o uso de substratos sólidos dificultaram a reprodutibilidade dos dados levantados. Erros de diluições, pesagens, pipetagens somados à ordem em que os elementos reacionais (tampão, extrato enzimático, substrato insolúveis ou solúveis) eram adicionados ao reator contribuíram para a pouca reprodutibilidade. Percebeu-se que, ao usar substrato sólido, era necessário primeiramente adicionar ao reator a solução de enzima e tampão, esperar a estabilizaçãoda temperatura deste meio, e em seguida adicionar o substrato sólido (papel). Isso reduziu consideravelmente os erros experimentais. Os dados obtidos são apresentados na Tabela 1.

Tabela 1 - Atividades total e individual do complexo enzimático CellicCtec2 Atividades

\begin{tabular}{c|c|c|c}
\hline FPase $(\mathrm{FPU} / \mathrm{mL})$ & Celobiase(UCB/mL) & CMCase $\left(\mathrm{U}_{\mathrm{CMC}} / \mathrm{mL}\right)$ & Avicelase $($ Uavicel $/ \mathrm{mL})$ \\
\hline $132,15 \pm 2,2$ & $6544,90 \pm 128,9$ & $2727,48 \pm 132,8$ & $45,60 \pm 3,5$ \\
\hline
\end{tabular}

\subsection{Imobilização de celulases}

A estratégia de imobilização adotada neste trabalho consiste na reação de grupos aminos presentes na superfície das enzimas com grupos aldeídos presentes na superfície do suporte (quitosana). A velocidade desta reação é favorecida em valores de $\mathrm{pH}$ acima de 8,0. Entretanto, as celulases de muitos complexos enzimáticos comerciais sofrem rápida inativação em valores de $\mathrm{pH}$ acima de 7,0. Apesar da baixa reatividade dos grupos aldeínosdo 
suporte com grupos aminos das enzimas em pH 5, um teste de imobilização das celulases nesta condição foi realizado com o objetivo de preservar a atividade catalítica das celulases, pois acreditava-se que em tempo relativamente longo $(24 \mathrm{~h})$ fosse possível observar uma completa imobilização das celulases.

Os dados da concentração de proteína no sobrenadante do sistema de imobilização no início $(\mathrm{t}=0)$ e final $(\mathrm{t}=24 \mathrm{~h})$ da reação a $\mathrm{pH}$ 5,0 não apresentou diferença significativa, indicando que não houve ligação da enzima ao suporte. Quando o experimento foi repetidoutilizando $\mathrm{pH} \mathrm{8,0} \mathrm{foi} \mathrm{observado} \mathrm{que} \mathrm{aproximadamente} 63 \%$ da proteína oferecida para a imobilização foi ligada ao suporte sem que uma perda de atividade significativa ocorresse. Apesar de algumas celulases presentes nos complexos enzimáticos comerciais apresentarem baixa estabilidade abaixo de $\mathrm{pH}$ 4,0 e acima de $\mathrm{pH}$ 7,0 a presença de vários tipos de aditivos em elevadas concentrações na formulação destes coquetéis fazem com que estas enzimas suportem melhor condições extremas de temperatura e $\mathrm{pH}$.As atividades de celulases solúveis e imobilizadas foram determinadas e estão resumidas na Tabela 2.

Tabela 2 - Atividades absoluta e específica de celulases imobilizadas em quitosana utilizando diferentes substratos

\begin{tabular}{c|c|cccc}
\hline \multicolumn{2}{c}{} & \multicolumn{4}{c}{ Substratos } \\
\cline { 3 - 6 } \multicolumn{2}{c}{} & a-Celulose & Celobiose & $\begin{array}{c}\text { Carboximetil- } \\
\text { celulose }\end{array}$ & Avicel \\
\hline \multirow{2}{*}{$\begin{array}{c}\text { Atividade } \\
(\mathrm{U} / \mathrm{mL} \\
\text { ou U/g) }\end{array}$} & Solúvel & $476,70 \pm 30,5$ & $6544,90 \pm 128,9$ & $2727,48 \pm 132,8$ & $45,60 \pm 3,5$ \\
\cline { 2 - 6 } & Imobilizada & $0,92 \pm 0,1$ & $8,69 \pm 0,2$ & $4,74 \pm 0,2$ & $0,13 \pm 0,0$ \\
\hline $\begin{array}{c}\text { Atividade } \\
\text { específica } \\
\left(\begin{array}{c}\text { U/mg } \\
\text { prot.) }\end{array}\right.\end{array}$ & Solúvel & $1,98 \pm 0,1$ & $33,20 \pm 5,7$ & $21,5 \pm 1,1$ & $0,39 \pm 0,0$ \\
\cline { 2 - 6 } & Imobilizada & $0,09 \pm 0,0$ & $0,90 \pm 0,0$ & $0,49 \pm 0,0$ & $0,01 \pm 0,0$ \\
\hline
\end{tabular}

As massas de celulase imobilizada utilizadas para determinação das atividades foram: 0,1 $\mathrm{g}$ ( $\alpha$-celulose), 0,025 $\mathrm{g}$ (carboximetilcelulose), 0,2 $\mathrm{g}$ (avicel) e 0,05 $\mathrm{g}$ (celobiose).A glicose liberada da hidrólise de $\alpha$-celulose foi medida após 0,5 e 18 h de reação. Na primeira medida, a glicose liberada pela enzima imobilizada $(0,14 \mathrm{mg})$ representava 5,9 \% da liberada pela enzima solúvel $(2,33 \mathrm{mg})$. Após 18 horas esse percentual aumentou para 11,0 \% (15,96 mg para enzima livre e $1,76 \mathrm{mg}$ para enzima imobilizada). Isto significa que a imobilização, apesar de reduzir a velocidade de hidrólise, causou alguma alteração na estrutura das celulases que aumentou sua estabilidade e/ou sua resistência à inibição, pois o desempenho desta melhorou em relação à enzima solúvel ao longo do tempo. Este resultado torna a estratégia de imobilização em quitosana promissora, e estudos posteriores visando reduzir o tamanho de partícula de quitosana e aumento da carga de celulase em sua superfície torna-se interessante.

Considerando a atividade específica em $\alpha$-celulose (U/mg de proteína) das celulases solúveis $(1,98 \mathrm{U} / \mathrm{mg})$ e imobilizadas em quitosana $(0,09 \mathrm{U} / \mathrm{mg})$, percebe-se a necessidade de aumentar a eficiência da enzima imobilizada. Resultados similares são observados para os demais substratos. A eficiência de celulases imobilizadas pode ser aumentada reduzindo o tamanho de partícula do suporte e evitando inativação da enzima durante o processo de imobilização. 
$\mathrm{Na}$ hidrólise de $\alpha$-celulose (30 minutos de reação) usando celulases solúveis e imobilizadas, experimentos variando a quantidade de biocatalisador foram realizados. Quando a quantidade de enzima solúvel foi aumentada cinco vezes (diluição de 1:100, ao invés de 1:500), a quatidade de glicose liberada aumentou somente $12 \%$ (de 2,6 mg para $30,7 \mathrm{mg}$ ). Enquanto isso, um aumento de cinco vezes da enzima imobilizada, levou a um acréscimo de $38 \%$ (de 0,5 mg para 19,0 mg). Ao elevar a concentração dascelulases solúveis no reator, eleva-se também a concentração de moléculas estabilizantes (glicose, glicerol, sorbitol, outras proteínas, etc.), presentes no extrato enzimático. Essas moléculas estabilizam as celulases, mas também inibem a ação das mesmas em concentrações elevadas. Estas moléculas são removidas no processo de imobilização, e a estabilidade da enzima passa a ser somente aquela adquirida pela imobilização.

\subsection{Hidrólise de biomassa pré-tratada usando celulases solúveis e imobilizada}

O desempenho do biocatalisador obtido foi avaliado na hidrólise de Brachiariabrizanthapré-tratada. Na amostra controle deste experimento, não foi verificado desprendimento de glicose, esta se manteve constante e baixa ao longo do tempo de hidrólise. Para os ensaios que empregaram a enzima imobilizada obteve-se, em média, 15,9 g/L de glicose, indicando conversão de $79,5 \%$ da celulose presente no meio e para a enzima livre esses valores foram de $4,85 \mathrm{~g} / \mathrm{L}$ de glicose ( $24 \%$ de conversão), vale ressaltar que foram adicionados ao reator as mesmas quantidades em unidades de atividade para enzima livre e imobilizada. Este é um bom resultado de hidrólise, entretanto, a quantidade do biocatalisador utilizada foi muito elevada $(1,09 \mathrm{~g})$ quando comparada à quantidade de substrato presente no reator $(0,3 \mathrm{~g})$.

O biocatalisador utilizado anteriormente foi recuperado e submetido a um novo ciclo de hidrólise, desta vez gerando uma concentração final de glicose de 10,5 g/L, o que corresponde a uma conversão de 52,5\%. Após o terceiro ciclo foi liberado 5,5 g/L de glicose, que representa uma conversão de $27,5 \%$. A redução no desempenho da celulase imobilizada ao longo dos três ciclos de hidrólise pode ser devido à inativação da enzima e maior dificuldade de agitação do meio reacional visto que o sólido remanescente da hidrólise anterior é carregado novamente no reator junto com a celulase imobilizada. Dois resultados importantes neste estudo foram obtidos, a obtenção de celulases ativas ligada a partículas sólidas e reuso desta enzima em processos de hidrólise de Brachiariabrizanthapré-tratada.

\section{CONCLUSÃO}

O uso da técnica de ligação covalente em quitosana permitiu a imobilização de todos os componentes celulolíticosdo extrato enzimático CellicCtec2, visto que o biocatalisador obtido foi eficaz na hidrólise de biomassa. Além disso, o desempenho da enzima imobilizada sobre a hidrólise de $\alpha$-celulose comparado ao da enzima solúvel melhorouao longo do tempo, provavelmente devido a estabilização e/ou resistência à inibição, ambos adquiridos após a imobilização. Apesar disso, o aperfeiçoamento no procedimento de imobilização ainda se faz necessário para que haja um aumento expressivo na quantidade de enzima imobilizada e melhoria na sua estabilidade. 


\section{REFERÊNCIAS BIBLIOGRÁFICAS}

ADRIANO, W.S. Preparação e caracterização de derivados de enzimas industriais em quitosana. Tese de doutorado, São Carlos, 2008.

BUDRIENE, S.; GOROCHOVCEVA, N.; ROMASKEVIC, T.; YUGOVA, V.L.; MIEZELIENE, A.; DIENYS, G.; ZUBRIENE, A. $\beta$ galactosidasefromPenicilliumcanescens. Properties and immobilization.Cent.Eur. J. Chem., v. 3, p. 95-105, 2005.

GHOSE, TK. Measurement of cellulase activities.Pure and Appl. Chem., v.59, p. 257-268, 1987.

GOUVEIA, R.; NASCIMENTO, R. T.; SOUTO-MAIOR, A. M; ROCHA, G. J. M. Validação de metodologia para a caracterização química de bagaço de cana-de-açúcar. Quím.Nova, v. 32, n. 6, 2009.

JORDAN, J.; KUMAR, C.S.S.R.; THEEGALA, C. Preparation and characterization of cellulase-bound magnetite nanoparticles.J. Mol. Catal. B: Enzym., v. 68, p. 139-146, 2011.

LIANG, W.; CAO, X. Preparation of a $\mathrm{pH}$-sensitive polyacrylateamphiphilic copolymer and its application in cellulase immobilization.Bioresour.Technol., v. 116, p. 140-146, 2012.

MAO, X. ; GUO, G.; HUANG, J.; DU, Z.; HUANG, Z.; MA, L.; LI, P.; GU, L. A novel method to prepare chitosan powder and its application in cellulase immobilization.J. Chem. Technol. Biotechnol., v. 81, p. 189-195, 2006.

OGEDA, T. L.; PETRI, D. F. S. Hidrólise enzimática de biomassa. Quím. Nova, São Paulo, v. 33 , n. 7, p. 1549-1558, 2010.

UNGUREAN, M.; PAUL, C.; PETER, F. Cellulase immobilized by sol-gel entrapment for efficient hydrolysis of cellulose.Bioprocess Biosyst. Eng., v. 36, p. 1327-1338, 2013.

VIEIRA, M.F., VIEIRA, A.M.S.; ZANIN, G.M.; TARDIOLI, P.W.; MATEO, C.; GUISÁN, J.M. $\beta$-Glucosidase immobilized and stabilized on agarose matrix functionalized with distinct reactive groups. J. Mol. Catal. B: Enzym., v. 69, p. 47-53, 2011.

XIAO, Z.; STORMS, R.; TSANG, A. Microplate-Based Filter Paper Assay to Measure Total Cellulase Activity.Biotechnol.Bioeng.,v. 88, n. 7, p. 832-837, 2004.

XU, Z.; MIAO, Y.; CHEN, J.Y.; JIANG, X.; LIN, L.; OUYANG, P. Co-immobilization Mechanism of Cellulase and Xylanase on a Reversibly Soluble Polymer. ApplBiochemBiotechnol, v. 163, p. 153-161, 2011.

ZHANG, Y.; XU, J.; LI, D.; YUAN, Z. Preparation and properties of an immobilized cellulase on the reversibly soluble matrix Eudragit L-100. Biocatal.Biotransform., $\quad \mathrm{v}$. 28, n. 5-6, p. 313-319, 2010. 